\title{
Research on Flipped Classroom Model and Teaching Platform for Software Engineering Professional
}

\author{
Haixia Sun, Deqing Zhang \\ Department of Computer Science and Technology \\ Anhui Sanlian University \\ Hefei, China \\ 284407152@qq.com
}

\begin{abstract}
The flipped classroom is a kind of teaching model of learning first then teaching, in order to get the good teaching result for the flipped classroom, on the one hand, we must make sure that the students can get the good learning result before the class, which is the premise and base for the classroom activities can move forward smoothly. On the other hand, for the software engineering students, their course's characteristics are strong practicality, which has the high requirement for the practice before and after class. This paper analyzes the problems which happened during the flipped class implementations ,and Put forward the corresponding teaching model for the flipped classroom, designs a corresponding teaching platform which combined cloud computing and mobile learning, analyze the main functional modules, provide references for the software engineering major's teaching reform.
\end{abstract}

Keywords-flipped classroom; teaching model; cloud computing; software engineering

\section{INTRODUCTION}

On July 2010, National medium and Long-term educational reform and development project summary (2010-2020) through the deliberations, brings educational informatization into national information development strategy. With the support of policy, china's education reform and education innovation is in full swing. From 2010 till now, the research on teaching theories of flipped classroom, micro lesson and mobile leaning turning into a gusher. The study is not only limited to theoretical research, but also a lot of colleges and universities have joined in the practice of flipped classroom. They actively summarize and explore during the practice, and form the suitable teaching model for their subject development. In China, the research on flipped classroom is from 2011, showing a large increase in quantity. However, compared with the western countries, in terms of theoretical research or model support or practical research, domestic research on translation classrooms is lacking in depth and width. Especially for a specific subject, to explore the suitable and professional teaching model for the subject's characteristics, and make the flipped classroom during the application process to avoid the phenomenon of acclimatized, which is our problem to be solved.

Software engineering has strong practicality, physical and practical characteristics. Students must through constant

Fund project: Large - scale online open courses in Anhui Province (MOOC) Demonstration project (2016mooc153) ; School level demonstration department of Network Engineering (16zlgc022) practice to master the methods of software development and thinking. At present, the software engineering course in colleges and universities still use the traditional teaching way, although the teaching plan consists of theory and practice of class, but the theory course emphasizes the explanations of the basic knowledge, based on teacher talk, and practice course based on the students "practice. This way makes the separation of theory and practice, it can't timely to consolidate the classroom knowledge, and the consistency is not strong. So we according to the characteristics of the professional courses of software specialty, we puts forward the teaching model of flipped classroom which is suitable for the software engineering specialty, and designs the supporting platform to carry on it.

\section{FEASIBILITY OF IMPLEMENTING FLIPPED CLASSROOM IN SOFTWARE ENGINEERING PROFESSIONAL}

The traditional teaching process includes two stages, one is a teacher as dominant, complete knowledge transfer through teaching in class, and the second is students through activities such as homework and practice after class to complete knowledge internalization.

The flipped classroom refers to the students carry out the independent learning according to their own time and learning characteristics to complete the knowledge transfer before class, and complete the process of knowledge internalization through interactive communication, cooperation and other forms of inquiry in class.

Flipped class compared with the traditional teaching model, students can arrange the study time and process according to their own situation, the learning autonomy belongs to themselves, which reflected the learners as the center, the teacher as the learning mentor during the learning process, the accords with constructivism theory and autonomous learning theory. Secondly, the basic knowledge of learning depends on students themselves, in some ways, which improve the students' learning ability. An important goal of higher education should be the cultivation of learning ability and the development of learning habits. During the teaching practices of flipped class, In order to ensure the teaching effect, we should not only consider the characteristics of the specialty, the characteristics of the course, but also consider the specific teaching situation of each school [1]. In view of the practical 
and engineering characteristics of the software engineering specialty, and general colleges and universities student's study condition, the following problems will be encountered in the implementation of the flip teaching:

\section{A. How to ensure students' learning time and effect before the glass}

College students' learning time relatively flexible, outside the classroom have more free time to disposal. Students can make full use of this period of time for autonomous learning, this is the foundation of the flip teaching can go smoothly.in order to ensure that most of the students can complete learning tasks and test before class, on the one hand,we can monitor the students' learning route, learning time and learning behavior in the teaching platform, and bring the students' learning process into the process of examination, which can promote the students' learning initiative; Secondly, when the teachers record the video resources, they must base on the students' attention concentration time and consider the convenience of students' learning, the video is based on micro video with a clear purpose and theme. The Students can learn through a variety of ways after the class, the computer professional students hold the computer rate at $100 \%$, hold the mobile-phone rate at $100 \%$, so students can according to their own situation, with computer and mobile terminal for learning and testing, without the limitation of time and space, to ensure adequate learning before class.

\section{B. How to organize effective teaching activities in class.}

Education needs face-to-face communication. If the learning before class is the foundation of flipped classroom, that classroom learning is the core which can keep the flip classroom going smoothly. To ensure the effect of classroom teaching, teachers first need to summarize according to students' learning situation before class, and focuses on the difficult point of teaching aims and students' doubt; Secondly, students can use the practice platform based on cloud computing to complete the practice task. Students must complete the relevant tasks in the specified time to complete the internalization of knowledge. In this process, teachers can follow the student's practice process and guide students individually. At the same time, the ability to work as a team is greatly enhanced in the process of group training.

\section{How to maximize improving the students' practical ability}

Specialized core course of software engineering, such as $\mathrm{C}$ language, data structure, operating system, specialized course such as JAVA object-oriented programming, Web application development, database systems, software engineering courses, all needs more practice. In the process of practicing students can deepen the understanding of theoretical knowledge and improve their practical ability. However, there are some problems such as lack of experimental resources, single form of experiment, teacher guidance cannot meet the needs of students, difficult to detect the experimental results at present practical teaching[2].In the implementation of flipped class for software engineering, on the one hand, teachers can intensify the practice in class, on the other hand, the teacher can constantly improve the teaching resource and project case of the cloud computing platform, after class students can Project actual combat according to their own needs, to improve their ability of engineering practice.

\section{How to evaluate the teaching effect}

At present, there are more and more schools joined the flipped classroom practice, and also give more optimistic data [3-4]. But this part of the data is based on students' test scores. But there are some literature data representation, that in the flip classroom, the students' performance is more active, also prefer to participate in class discussion, but after the test, they found that the use of flipping teaching methods is not impact too much to the test results [5].Therefore, in the implementation of the flip classroom, need to establish a set of evaluation system based on the process, which not only consider the students' periodic examination result, also consider the students learning enthusiasm after class and learning process, and the team cooperation ability in class, finishing status of the classroom practice and the classroom interaction etc., these all depend on the perfect learning process monitoring mechanism.

In addition, using the flip classroom, the teachers' ability and quality also put forward a great challenge. Whether the flipped classroom can be effectively implemented, teachers occupy a very important position. From the pre-class highquality teaching video production, the summary of the problem before the class, and then to the organization capacity in the class, teachers need to constantly learning from all aspects to improve.

\section{ANALYSIS AND DESIGN OF FLIPPED CLASSROOM TEACHING MODEL}

These years, domestic and foreign scholars have put forward different flip classroom teaching model. A typical system structure model is summarized by Professor Robert Talvert from Franklin College of the United States. The flipped classroom is divided into two stages, which is before class and in class. Students complete the learning of basic knowledge by watching the video and targeted exercise before class, and solve difficult problems to complete the internalization of knowledge in class. In china, the typical flipped classroom teaching model is constructed by Zhang Jinlei and Zhong XiaoLiu. Knewstubn and Bernadette focus on the relationship between learning and teaching in their LTN teaching model [6] Bronson Carroll and Dentith Audreym studied relation between teachers and students and the importance of cooperation between them. To improve the teaching cooperation in the relationship, it is important to improve teaching skills as a support [7].In the process of teaching, the school should make their own teaching mode according to their own training target and plan, cannot follow others blindly.

Considering the software professional course, need to have more practice to enhance its practical ability, we proposed software professional flip classroom teaching mode. This kind of teaching mode, emphasize the role of the teaching platform and the process of appraisal and project practice, the whole teaching process are relying on the perfect teaching platform.

Teachers divided the teaching task into multiple clear teaching goals according to the syllabus and class hour 
arrangement. The whole teaching is conducted around the teaching goal. Each teaching goal is acted as a teaching cycle, and the teaching model of each teaching cycle as shown in Figure 1 below:

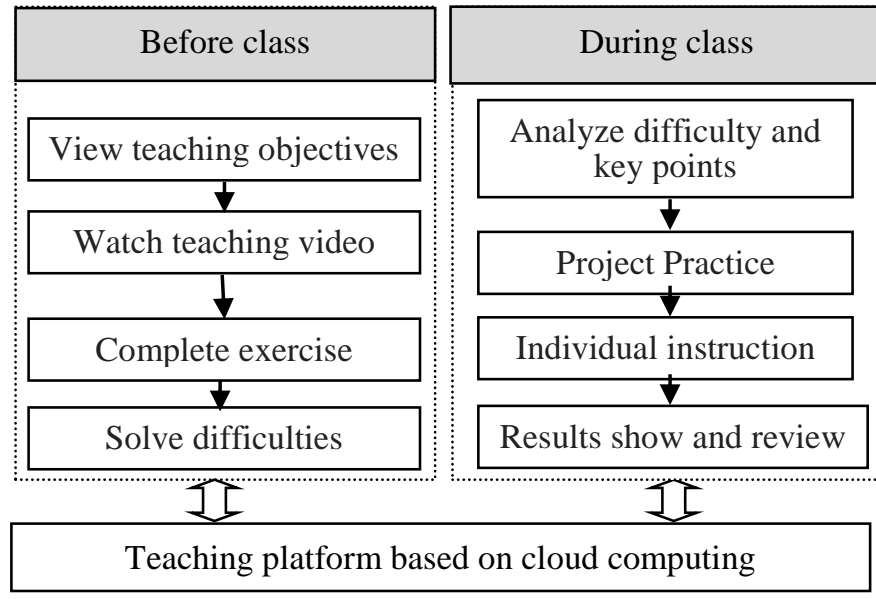

Fig. 1. Software professional flipped classroom teaching model

\section{A. Learning and testing before class}

Full learning before class is the premise for classroom activities going smoothly .According to teaching goal, the teachers make the teaching video, audio, teaching courseware and reference materials, and upload them to the teaching platform.at the beginning of each teaching period, the students need to view the teaching goal and problems, then watch the video with the questions. Later, students finish the test and evaluation. If the students have questions, they can upload the problem to the platform and the teacher will answer them on the platform. Learning before class as the first half of the teaching period, not only have a clear task to complete, but also have a time limited, students must complete all the learning and testing tasks all 24 hours before class, to give the teacher enough time to sum up, to prepare for the class difficult point analysis.

Pre class learning and evaluation is the basis for the smooth progress of the classroom teaching, so each operation by the students is recorded into the teaching platform, as a means of the supervision of students' learning, which is always stressed, can't depend entirely on the students' learning initiative.

\section{B. $\quad$ Knowledge internalization in class}

Before the class, the teacher summarizes the questions raised by the students in the teaching platform, and collated the exercises with higher error rate.in Class the first task is to complete the knowledge difficulty analysis and parsing, and help students to understand related knowledge. After that, students have mastered most of the teaching content in the teaching cycle. But according to pyramid theory, we know if the software engineering students want to complete the knowledge internalization, it is necessary to apply the theory to the practical project. So the second stage is to require students to complete the project practice by group. This project is for the objective and appropriate difficulty; students are required to finish within the prescribed time. During this process, if the team members meet the problems, they can discuss with each other, help each other, or ask questions to the teacher. Students can continuously think in the project practice, improve their theoretical level and practical ability.

\section{DESIGN OF CLOUD COMPUTING TEACHING PLATFORM}

In order to guarantee the successful implement of flip classroom, achieve good teaching effect, which can't depart from the support of functional teaching platform. The construction of the cloud computing teaching platform can flip the teaching and learning with science and technology, which is an effective modern technology to implement flipped classroom. Especially for software professional which is a relatively practical professional, need more support of teaching platform. There are a lot of precedents in china. Such as Wuhan University of Technology, who has set up a computer experimental teaching platform based on cloud computing [8]. And another example is the cloud computing training platform which is built by JiShou University. In the experimental platform, students can experience the enterprise working environment, training to real projects; effectively improve the teaching effect and teaching efficiency. There are the teachers or scholars using the existing teaching platform to practice the flip classroom teaching, such as teaching practice based on the World University City cloud platform. With the demand of the school and this major, we designed a teaching platform which combined cloud computing and mobile learning, its main function module of teaching resources management, experimental platform, process evaluation, etc., as shown in Figure 2:

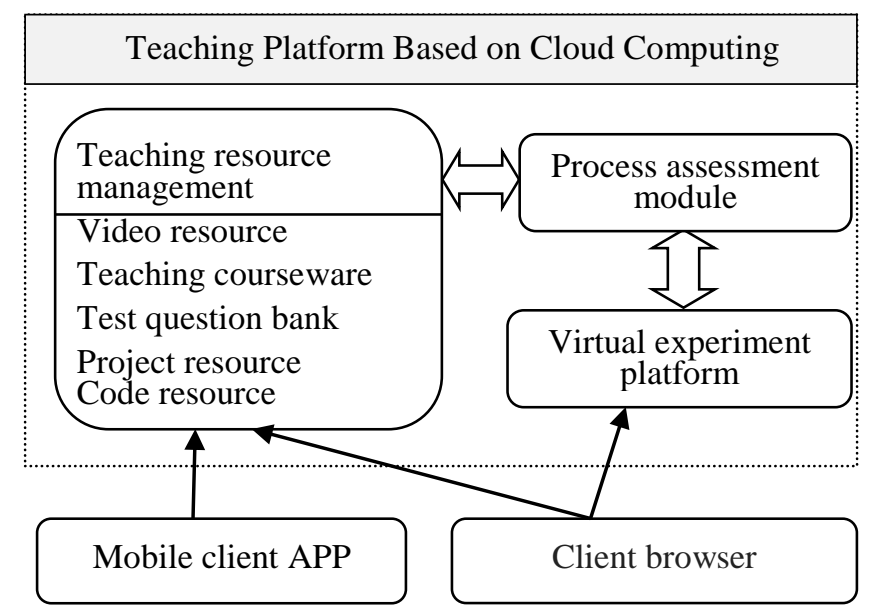

Fig. 2. The Framework of Teaching Platform Based on Cloud Computing

\section{A. Teaching resource management module}

Students' autonomous learning new knowledge way is varied. But through the online survey, more than $70 \%$ of the students prefer watching video to learn new knowledge, Therefore, teaching video release and management is most important in the teaching resource management module. Because the teaching goal is divided into a number of knowledge points, when the teacher is recording the teaching video, they must keep each video around a knowledge point 
with clear subject and purpose, time control within 10 minutes. The second part of the Teaching resources management module is the management of the Practice question bank, we divide the practice into two kinds, one kind is for specific knowledge practice, if the students grasp the knowledge points not very well, make the mistake in the practice, they can repeat to watch video to learn; Another kind is for comprehensive practice of multiple objective, inspecting the students' comprehensive application ability of the multiple knowledge , this is to avoid the risk of flip classroom's knowledge fragmentation. Thirdly, for software engineering students, through project practice to constantly improve their operational ability, so the project maintenance, source code management is also very important.

\section{B. Virtual experiment platform}

Cloud computing teaching platform not only provides the various learning resources for the students, it also provides the necessary practice environment for the students, so the students can conduct the experiments through the network access platform , and Individual test status and time information will be recorded.

\section{Process assessment module}

If students' autonomous learning ability is bad, can't finish the video learning and practice evaluation before class, then the related links cannot go smoothly in the class. Therefore, the process assessment module in the teaching platform has a very important position, the teacher can check the students watching the video teaching's time, check the progress of the exercise and the result of the exercise through the teaching platform, and then understand the students' learning status, monitoring the students' learning process, and put this part into the final student achievement evaluation, in this way to promote students' autonomous learning.

With the popularity of mobile devices and the further research of mobile learning, In addition to the cloud computing teaching platform, the system provides mobile learning APP, so that the students can learn without the limited of the time and space. In addition to the function of the virtual experimental platform, all the other functions can be implemented with APP.

\section{CONCLUSION}

The teaching video and teaching resources on the teaching platform can be reused. So teachers' teaching more targeted. Teachers can teach the important and difficult points according to the characteristics of each group of students, not limited to the duplication of basic knowledge, in this way to improve the working efficiency and enhance the teaching effect. The main features of software engineering professional flipped teaching model are:

- Knowledge transfer occurred before the class, students are required to complete the knowledge learning before the class and complete the corresponding practice;

- Through the practice to Complete the knowledge internalization occurred in the class;

- Strengthen the intensity of practice. The teacher arranges the objective practice task in the class, and students practice through the cloud platform to improve the students' practical ability;

- With the mobile learning APP, convenient for students to learn without the limited of time and space;

- Assessment and evaluation run throughout the whole teaching process. Students learning process and status have been recorded before the class, as the basis of the usual scores, the practice in the class also been included into the assessment process, from different aspects to ensure the students' learning autonomy.

\section{REFERENCES}

[1] ChunMei Yang . Summary of the Research on the Teaching of Higher Education[J]. Higher Education in Jiangsu Province, 2016(1): 59-63.(in chinese)

[2] Yun Huang, JiaMing Hong. Experimental Teaching Reform of Foundation of ProgrammingDesign Based on Cloud Platform [J]. Laboratory Research and Exploration, 2016 (2): 191-195. (in chinese)

[3] JianPing Hu. Canvas Supported Flipped Classroom: the Case of the CourseFLASH Animation Design [J]. Distance education in China,2014,(9): 72-77. (in chinese)

[4] TengFei Cao,ZhiQiang Liu. Research on experimental teaching of pjoect-driven and flipped class based on fundamentals of database applications[J]. Experimental Technology and Management, 2015(11): 206-208, 211. (in chinese)

[5] Sidney Man-ngai Chan, Jean Yuk-tin Tse. the flipped classroom in an undergraduate nutritional science course.https://link.springer.com/article/10.1186/2193-1801-4-S2-P3.

[6] Knewstubn, Bernadette. The Learning-teaching nexus: modelling the learning-teaching relationship in higher education[J]. Studies in Higher Education.2016,41(3):525-540.

[7] Bronson Carroll, Dentith Audreym. Partner Teaching: a Promising Model[J].Education Summer.2014,134(4):506-520.

[8] YanChao Yang. Canvas Supported Flipped Classroom: the Case of the CourseFLASH Animation Design [J]. Experimental Technology and Management, 2016, 33(10): 147-151. (in chinese) 